\title{
¿Qué es leer? \\ La lectura y su representación en estudiantes universitarios
}

Silvia del Carmen Miramontes Zapata, ${ }^{1}$ Juan Martín Sáncez Bautista ${ }^{1}$ y Sandra Ramos Basurto ${ }^{1}$

\section{Introducción}

La lectura es una habilidad fundamental que permite a las personas adquirir conocimiento proveniente del material escrito y desarrollar destrezas en el procesamiento de la información. Asimismo, es el principal medio del lenguaje, es un factor determinante del éxito o del fracaso escolar, expande la memoria humana y moviliza activamente la imaginación creadora del individuo, entre otras cosas (Condemarín, 2001).

Siendo una actividad intelectual imprescindible tanto dentro de la vida cotidiana como del ámbito académico, vale la pena preguntarse acerca de su significado.

Para Rueda (2003), leer, en su concepción básica, puede entenderse como simple decodificación, por lo que en este sentido existe una diferencia entre leer (decodificar) e interpretar lo leído (comprender). Para la mayoría de los especialistas en el área, la lectura como decodificación sin comprensión es una

1 Universidad Autónoma de Zacatecas. 
actividad vacía, por lo que el verdadero significado de leer es el producto de lo que de ella se obtiene (Solé, 2001; Perfetti y Hart, 2001; Perfetti, 2007; Vallés y Vallés, 2006; entre otros).

González (2005) sugiere que este término puede tener dos referentes. El primero de ellos es "aprender a leer", cuya principal actividad es la decodificación, siendo ésta condición necesaria para acceder a sus significados. El segundo es "aprendizaje a partir de textos": es decir, implica la construcción de una representación mental compleja y elaborada en forma jerárquica y su correspondiente integración a los conocimientos previos. Podría decirse, por tanto, que leer y comprender resultan dos conceptos inseparables o, al menos, fácilmente asociables entre sí.

\section{Redes semánticas naturales}

De acuerdo a Szalay y Bryson (1974, citado en Valdez, 2000: 15), las redes semánticas son: "[...] la unidad fundamental de la organización cognoscitiva, compuesta de conocimientos y efectos, que crea un código de reacción, los cuales reflejan la imagen del universo y la cultura subjetiva de las personas". En este sentido, podemos considerar que las redes semánticas son representaciones hipotéticas de nuestras estructuras de conocimiento que permiten explicar las reglas de uso de conceptos y las relaciones entre ellas.

A partir de la aparición de la técnica de redes semánticas naturales, propuesta por Figueroa, Gonzáles y Solís en 1981 (Valdez, 2000), se tiene un modo de investigar los significados directamente con humanos, en forma natural, evitando así las simulaciones y las categorizaciones de corte meramente hipotético, así como la utilización de taxonomías artificiales creadas por los investigadores (Valdez, 1998: 65).

De esta manera, la técnica ofrece un panorama de los significantes internos que poseen las personas al respecto de lo que los rodea, además de dar a conocer la forma en la que los sujetos fueron adquiriendo dicha información a través de un aprendizaje social, ya que, "ofrece un medio empírico de acceso 
a la organización cognitiva del conocimiento [...] y provee indicios fundamentales acerca de la tendencia a actuar, basándose en ese 'universo cognitivo'” (Vera, Pimentel y Batista, 2005: 442).

Por tanto, el valor que tiene el uso de la técnica de redes semánticas naturales reside en qué información y categorización de ésta son generadas por la memoria semántica del sujeto y de acuerdo a su escala de valores y percepciones (Zermeño, Arellano y Ramírez, 2005).

\section{Material y métodos}

El presente estudio tuvo como objetivo conocer el significado psicológico que tienen los estudiantes de Psicología sobre las palabras leer y comprender. Se realizó con alumnos de primer y cuarto año de la Unidad Académica de Psicología (UAP), Campus Zacatecas, de la Universidad Autónoma de Zacatecas "Francisco García Salinas". La selección de los participantes fue a través de un muestreo aleatorio simple, considerando como universo las listas de alumnos inscritos en la UAP. La muestra quedó conformada por 120 alumnos, 32 hombres y 88 mujeres. La edad promedio de los participantes fue de 18 años (entre 17 y 21 años).

Se utilizó la técnica de redes semánticas naturales. La aplicación del instrumento se llevó a cabo en el salón de videoconferencias de la UAP, Campus Zacatecas, con las instrucciones acordes a lo sugerido por Valdez (2000). En primer lugar, se pidió a los participantes que definieran una palabra estímulo con un mínimo de 5 palabras (no frases), que podían ser nombres, pronombres, sustantivos, adjetivos, verbos, y adverbios, sin utilizar preposiciones, conjunciones, artículos o cualquier otro tipo de palabras gramaticales.

Posteriormente, se les pidió jerarquizar las palabras a partir de la importancia que cada una de ellas tiene a juicio de la persona que las produce, respecto a la palabra estímulo que definieron. De esta manera, se le pide que asignen el número uno a la más importante, relacionada o que mejor define a la palabra estímulo, el número dos a la que le sigue en importancia, el tres 
a la siguiente y así sucesivamente hasta terminar de jerarquizar todas las palabras definidoras.

Con el objetivo de que las instrucciones fueran claras, se dio como ejemplo la palabra estímulo "manzana", acto seguido, se les pidió que dijeran en voz alta palabras que, a su juicio, la definieran, como "fruta", "roja", etcétera; finalmente, se les pidió que jerarquizaran dichas palabras, poniendo en primer lugar la que mejor la describe. Concluido el ejemplo, se prosiguió con el estudio.

Para la presente investigación, se utilizaron las palabras estímulo "Leer" y "Comprender". Esto se hizo por escrito e individualmente.

Para el análisis, se capturaron en el programa Excel cada una de las palabras definidoras que todos los participantes escribieron para cada una de las dos palabras estímulo. Se le asignó una puntuación inversa a la otorgada por los participantes (por ejemplo, a los términos descriptores que tenían el primer lugar, por ser los que más describían los conceptos, se les asignó el valor de 10; a los que aparecían en segundo lugar, 9, y así sucesivamente). Posteriormente, se sumaron el total de descriptores escritos por todos los integrantes, lo que dio el valor J. Se seleccionaron los diez descriptores con mayor puntuación. Este listado constituye el Conjunto SAM. El valor m lo conforma la sumatoria de cada una de las palabras definidoras que conforman el Conjunto SAM. Finalmente, el valor FMG se obtuvo a partir de una regla de tres, en la que se tomó como referencia la palabra del Conjunto SAM con el valor m más grande, la que representó 100\%.

\section{Resultados y discusión}

Una vez realizado el análisis de las palabras definidoras y conformado el Conjunto SAM, el valor J, el valor m y el valor FMG, se presentaron los datos para su interpretación. Los resultados obtenidos a través de la técnica de redes semánticas naturales se señalan y discuten en el orden siguiente. En primer lugar, se indican los resultados relativos a la palabra estímulo "Leer", y posteriormente los resultados de la palabra estímulo "Comprender". 
Los resultados de la palabra estímulo "Leer" encontrados fueron los siguientes. El valor J fue de 230. Dada la edad de los sujetos y el nivel académico que tienen, éste resultado podría considerarse esperable. En un estudio previo, realizado por Zermeño, Arellano y Ramírez (2005), se encontró que el valor J correspondía al lugar de origen de sus participantes (urbano/rural). Encontraron que el promedio del valor j oscilaba entre 0.84 y 1.11, respectivamente. En los resultados del presente estudio, el promedio del valor j fue de 1.9. Este valor es muy importante, pues permite conocer la estrechez o amplitud del vocabulario que poseen los participantes, así como su visión del mundo.

En el conjunto SAM (las definidoras con mayor peso semántico), se encontraron las siguientes diez palabras definidoras: Libro (valor м: 562; valor FMG: 100); Letras (valor м: 325; valor FMG: 57.8); Texto (valor м: 315; valor FMG: 56.4); Aprender (valor м: 308; valor FMG: 54.8); Comprender (valor M: 295; valor FMG: 52.4); Conocimiento (valor м: 237; valor FMG: 42.1); Atención (valor м: 110; valor FMG: 19.5); Información (valor M: 94; valor FMG: 16.7); Escuela (valor м: 73; valor FMG: 12.9); Analizar (valor м: 72; valor FMG: 12.8).

Como se habrá notado en los resultados anteriores, las tres palabras definidoras que tienen tanto el valor $\mathrm{M}$ como el FMG mayor, corresponden a objetos concretos (Libros, Letras, Texto), mientras que el resto corresponde al significado profundo de leer (Aprender, Comprender, Conocimiento, Atención, Información, Escuela y Analizar), es decir, como mencionan la mayoría de las definiciones del concepto "leer", es una actividad que necesariamente debe atribuirse a la extracción de significados. Al parecer, podría decirse que esto es lo que leer les significa a los participantes de este estudio; sin embargo, es importante precisar que esos significados están asociados a cuestiones más escolares que lúdicas. Por ejemplo, la palabra definidora "Divertido" tiene un valor m de 14, y la de "Hobbie", 3.

Con respecto a la palabra estímulo "Comprender", los resultados igualmente son alentadores. El valor j fue de 243 (2.02 en promedio por participante). El conjunto SAM se compuso de las siguientes palabras definidoras: Entender (valor м: 559; va- 
Ior FMG: 100); Analizar (valor M: 352; valor FMG: 61.8); Aprendizaje (valor м: 327; valor FMG: 57.4); Leer (valor м: 265; valor FMG: 46.577); Atención (valor м: 189; valor FMG: 33.2); Pensar (valor M: 156; valor FMG: 28.4); Razonar (valor M: 133; valor FMG: 23.3); Explicar (valor м: 132; valor FMG: 23.1); Saber (valor м: 127; valor FMG: 22.3); Texto (valor M: 104; valor FMG: 18.2).

Llama la atención que dentro del conjunto sam, existen dos palabras definidoras que tienen relación con la lectura y que otras tres son compartidas con la palabra estímulo "Leer". El resto de las palabras definidoras podrían asociarse con procesos cognitivos básicos.

\section{Conclusiones}

Como habrá podido notarse, las palabras estímulo "Leer" y "Comprender" comparten varias definidoras entre ellas. Estos resultados muestran que, para los participantes de este estudio, ambos conceptos resultan inseparables, tal como lo señalan algunas definiciones hechas por investigadores especializados en el área. Pudo notarse que leer, para los participantes, significa la extracción de significados, es decir, han superado la etapa de aprender a leer y han pasado a la de leer para aprender.

En este punto es importante remarcar dos cuestiones. La primera está relacionada con el tipo de participantes del presente estudio (estudiantes de licenciatura), pues seguramente dentro de sus tareas habituales se encuentra la revisión de un texto escrito; y la segunda, que el hecho de que leer les signifique algo valioso no necesariamente implica que tengan como hábito leer. A decir de la Encuesta Nacional de Lectura (2006), 30.4\% de los mexicanos señaló haber leído un libro en algún momento de su vida, mientras que $12.7 \%$ dijo nunca haber leído un libro. El promedio de libros leídos al año por personas con estudios universitarios es de 5.1. Lo que no nos pone en un lugar ventajoso con respecto a otros países. 


\section{Referencias}

Condemarín, M. (2001). El poder de leer. Chile: Ministerio de Educación.

INEGI. (2006). Encuesta Nacional de Lectura. México: INEGI.

González, M.C. (2005). Comprensión lectora en niños: morfosintaxis y prosodia en acción. Tesis doctoral. Universalidad de Granada.

Perfetti, C. (2007). Reading Ability: Lexical Quality to Comprehension. Scientific Studies of Reading, 11(4), 357-383.

Perfetti, C. y Hart, L. (2001). The Lexical Bases of Comprehension Skill. En D.S. Gorfien (Ed.). On the Consequences of Meaning Selection: Perspectives on Resolving Lexical Ambiguity, (67-86). Washington, D.c.: American Psychology Association.

Rueda, M.I. (2003). La lectura: adquisición, dificultades e intervención. Salamanca: Amarú.

Solé, I. (2001). Estrategias de lectura. Barcelona: Graó.

Valles, A. y Vallés, C. (2006). Comprensión lectora y estudio. Intervención Psiopedadógica. Valencia: Promolibro.

Valdez, J.L. (1998). Las redes semánticas naturales. Usos y aplicaciones en Psicología Social. México: UAEM.

Valdez, J.L. (2000). Las redes semánticas naturales. Usos y aplicaciones en Psicología Social ( $3^{\mathrm{a}}$ ed.). México: UAEM.

Vera, J.L., Pimentel, C.E. y Batista, F.J. (2005 Septiembre-Diciembre). Redes semánticas. Aspectos teóricos, técnicos, metodológicos y analíticos. Ra Ximhai, 1(3), 439-451.

Zermeño, A.I., Arellano, A.C. y Ramírez, V.A. (2005, diciembre). Redes semánticas naturales: técnica para representar los significados que los jóvenes tienen sobre televisión, Internet y expectativas de vida. Estudios sobre las Culturas Contemporáneas. Época II, 11(22), 305-334. 
